\title{
Preparation, Characterization, and Photocatalytic Properties of Modified Red Mud
}

\author{
Mingjie Ma, Guanyu Wang, Zhengpeng Yang, Shanxiu Huang, Weijie Guo, and Yuxia Shen \\ School of Materials Science and Engineering, Henan Polytechnic University, Jiaozuo 454000, China \\ Correspondence should be addressed to Zhengpeng Yang; zhengpengyang2013@163.com
}

Received 29 May 2015; Revised 11 July 2015; Accepted 14 July 2015

Academic Editor: Luigi Nicolais

Copyright (C) 2015 Mingjie Ma et al. This is an open access article distributed under the Creative Commons Attribution License, which permits unrestricted use, distribution, and reproduction in any medium, provided the original work is properly cited.

\begin{abstract}
Solid waste red mud was modified by $\mathrm{HCl}$ leaching. The structure property and composition of modified red mud were investigated by X-ray diffraction (XRD), X-ray fluorescence spectroscopy (XRF), scanning electron microscopy (SEM), and Brunauer-EmmettTeller (BET). Under UV irradiation, methyl orange (MO) aqueous solution was photodegraded by modified red mud. The obtained results showed that the specific surface area of modified red mud was $317.14 \mathrm{~m}^{2} / \mathrm{g}$, which was about 40 times higher than that of the normal red mud. After UV irradiation for $50 \mathrm{~min}$, the removal percentage of MO reached $94.2 \%$. The study provided a novel way for the application of red mud to the photocatalytic degradation of organic wastes.
\end{abstract}

\section{Introduction}

Red mud is a kind of solid waste produced in the smelting process of aluminium. On account of more chemical alkali, metal oxide and radioactive substance present in red mud, the harmless utilization of red mud is difficult [1]. Over the years, many researchers all over the world pay an increasing attention to the utilization of red mud but got a little [2,3]. Thus, it is desirable to search for a novel method to better realize the utilization of red mud.

Red mud contains many metal oxides, such as $\mathrm{Al}_{2} \mathrm{O}_{3}$, $\mathrm{Fe}_{2} \mathrm{O}_{3}, \mathrm{SiO}_{2}, \mathrm{CaO}$, and $\mathrm{TiO}_{2}$ [4]. Among them, $\mathrm{TiO}_{2}$ with excellent photocatalytic properties provides the possibility for the efficient utilization of red mud in photocatalytic field. $\mathrm{TiO}_{2}$ as semiconductor photocatalyst has been widely applied in many fields due to its nontoxicity, high photocatalytic activity, and stability [5-7]. Photocatalytic property of $\mathrm{TiO}_{2}$ can be attributed to the holes produced in the valance band under light irradiation, the valence band $\left(\mathrm{h}_{\mathrm{vb}}{ }^{+}\right)$potential is positive enough to generate the hydroxyl radicals, and the resulting hydroxyl radicals are a very strong oxidizing agent which can oxidize the organic pollutants into $\mathrm{H}_{2} \mathrm{O}$, $\mathrm{CO}_{2}$, and other small molecules $[8,9]$. In addition, the other metal oxides (e.g., $\mathrm{Al}_{2} \mathrm{O}_{3}, \mathrm{Fe}_{2} \mathrm{O}_{3}$, and $\mathrm{SiO}_{2}$ ) in red mud are good for the enhancement of photocatalytic activity of $\mathrm{TiO}_{2}$.
$\mathrm{Al}_{2} \mathrm{O}_{3}$ and $\mathrm{SiO}_{2}$ can enhance the adsorption of substances onto the photocatalyst and prevent the recombination of photogenerated electron-hole, causing a high photocatalytic efficiency $[10,11]$. $\mathrm{Fe}_{2} \mathrm{O}_{3}$ can cause a decrease in the band-gap energy of $\mathrm{TiO}_{2}$, which is favorable for its photocatalysis [12]. To the best of our knowledge, the photocatalytic application of red mud or modified red mud is still rarely reported.

In this work, the modified red mud was prepared by a simple $\mathrm{HCl}$ leaching process. The resultant modified red mud was used for the photocatalytic degradation of $\mathrm{MO}$ which was selected as a model of organic pollutants. The composition, morphology, and structure of the modified red mud were characterized by XRD, XRF, SEM, and BET. The photocatalytic performance of the modified red mud under UV irradiation was also examined in detail.

\section{Experimental}

2.1. Preparation of Modified Red Mud. Red mud produced by Bayer process [13] was dried at $110^{\circ} \mathrm{C}$ for $2 \mathrm{~h}$ and then crushed into $2 \mathrm{~mm}$. Subsequently, $30 \mathrm{~g}$ of red mud was mixed with $90 \mathrm{~g} \mathrm{HCl}(5 \mathrm{~mol} / \mathrm{L})$ in the beaker under vigorous stirring, and the obtained uniform mixture was placed in the water bath $\left(60^{\circ} \mathrm{C}\right)$. After incubation for $1 \mathrm{~h}$, the mixture was separated by suction filtration and then washed with deionized water until 
the neutral mixture was obtained. Finally, the mixture was dried at $110^{\circ} \mathrm{C}$ for $1 \mathrm{~h}$, and the modified red mud was prepared.

2.2. Characterization. XRD was performed on a Rigaku $\mathrm{X}$-ray diffractometer with $\mathrm{Cu}-\mathrm{Ka}$ radiation (Bruker D8 ADVANCE diffractometer, $\lambda=1.5406$ À). The chemical composition was analyzed by sequential wavelength dispersive XRF (Panalytical Axios) at an accelerating voltage of $4 \mathrm{kv}$. The morphology was examined on SEM (JSM 6700F) at an accelerating voltage of $10 \mathrm{kv}$. The specific surface area and pore diameter distribution curves were obtained from the Autosorb-IQ-MP automatic gas analyzer at $77 \mathrm{k}$. The concentration of $\mathrm{MO}$ was determined by an $\mathrm{UV} / \mathrm{vis}$ spectrophotometer (UV-1601, Shimadzu, Japan).

2.3. Photocatalytic Experiment. The photocatalytic experiments were carried out in a water-jacket reactor at a constant temperature of $10^{\circ} \mathrm{C}$ and initiated by irradiating with a 175 $\mathrm{W}$ high-pressure mercury lamp $(\lambda=315-350 \mathrm{~nm})$, and the distance between the water-jacket reactor and lamp was kept at $15 \mathrm{~cm}$. In every experiment, $70 \mathrm{mg}$ of test sample and $100 \mathrm{~mL}$ of $5 \times 10^{-5} \mathrm{~mol} / \mathrm{L} \mathrm{MO}$ aqueous solution were introduced in the reactor with magnetic stirring. $5 \mathrm{~mL}$ of the irradiated solution was extracted from the reactor at certain intervals. After centrifugal separation, the concentration of MO was analyzed by a UV-vis spectrophotometer at $\lambda_{\max }=$ $464 \mathrm{~nm}$. The removal percentage of MO was calculated by the equation:

$$
\text { photodegradation rate }=\frac{C_{0}-C_{t}}{C_{0}} \times 100 \%,
$$

where $C_{0}$ represents the initial concentration of the $\mathrm{MO}$ solution and $C_{t}$ is the concentration at time $t$.

\section{Results and Discussion}

3.1. Material Characterization. The chemical compositions of red mud and modified red mud were identified by XRF. As seen in Table 1, the main compositions of red mud were $\mathrm{Al}_{2} \mathrm{O}_{3}, \mathrm{SiO}_{2}$, and $\mathrm{CaO}$, which were about $60 \%$ of total red mud. Other compositions were mainly composed of $\mathrm{Fe}_{2} \mathrm{O}_{3}$, $\mathrm{TiO}_{2}$, and some metal elements (Sr, Zr, etc.) [14]. After $\mathrm{HCl}$ leaching, compared with the red mud, the amounts of $\mathrm{Al}_{2} \mathrm{O}_{3}, \mathrm{SiO}_{2}, \mathrm{Fe}_{2} \mathrm{O}_{3}$, and $\mathrm{CaO}$ in modified red mud were obviously decreased, whereas the amount of $\mathrm{TiO}_{2}$ was slightly increased. Such results can be closely related to the $\mathrm{HCl}$ leaching, $\mathrm{HCl}$ can react with $\mathrm{Al}_{2} \mathrm{O}_{3}, \mathrm{SiO}_{2}, \mathrm{Fe}_{2} \mathrm{O}_{3}$, and $\mathrm{CaO}$, while $\mathrm{TiO}_{2}$ was stable in $\mathrm{HCl}$ solution, causing an increasing percentage of $\mathrm{TiO}_{2}$ and a loss of $\mathrm{Al}_{2} \mathrm{O}_{3}, \mathrm{SiO}_{2}, \mathrm{Fe}_{2} \mathrm{O}_{3}$, and $\mathrm{CaO}$. The increase of $\mathrm{TiO}_{2}$ amount in modified red mud will be favorable for its photocatalytic application.

The composition and crystal structure of modified red mud were identified by XRD. As seen in Figure 1, the diffraction peaks at $2 \theta=25.4^{\circ}, 37.8^{\circ}, 55^{\circ}$, and $62.6^{\circ}$ can be perfectly indexed to those XRD patterns of anatase $\mathrm{TiO}_{2}$ nanoparticles [15]. XRD analysis strongly confirmed that $\mathrm{TiO}_{2}$ existing in modified red mud belonged to anatase.
TABLE 1: The chemical composition of red mud and modified red mud.

\begin{tabular}{lcccccc}
\hline Sample & $\mathrm{Al}_{2} \mathrm{O}_{3}$ & $\mathrm{SiO}_{2}$ & $\mathrm{Fe}_{2} \mathrm{O}_{3}$ & $\mathrm{TiO}_{2}$ & $\mathrm{CaO}$ & Others \\
\hline Red mud (\%) & 26.22 & 20.52 & 5.71 & 5.3 & 17.28 & 24.97 \\
Modified red mud (\%) & 18.34 & 17.89 & 2.86 & 6.79 & 7.36 & 50.00 \\
\hline
\end{tabular}

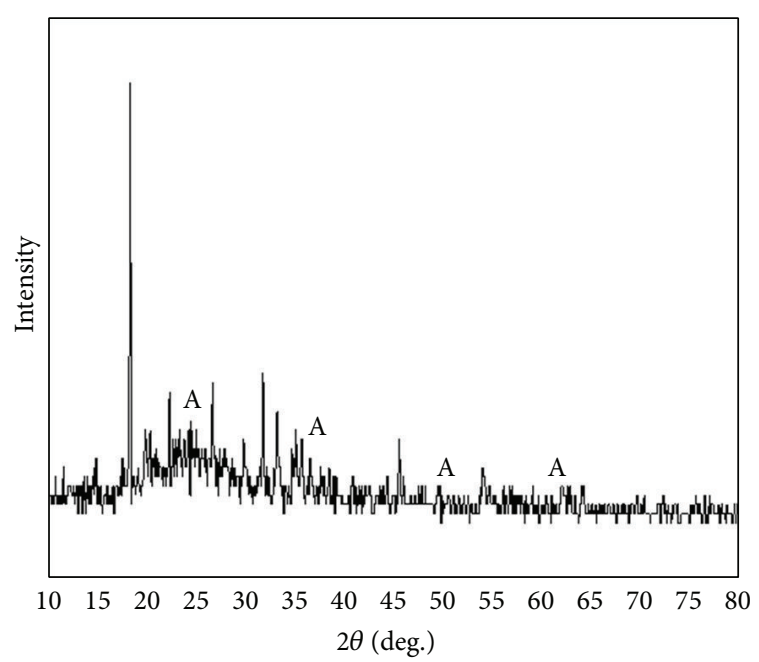

A: anatase

FIGURE 1: XRD pattern of modified red mud.

The morphology of red mud and modified red mud was characterized by SEM. As shown in Figure 2, the red mud was composed of coarse, angular, and irregular particles, and the large fracture and divaricate structure were present on its surface. Compared with red mud, the size of fracture in modified red mud was decreased, and many nearly spherical particles appeared on the surface of modified red mud. Such phenomena may be attributed to the $\mathrm{HCl}$ leaching, causing the dissolution of metal oxide on the surface of red mud.

Specific surface areas of red mud and modified red mud were characterized by BET. Figure 3 shows the isotherm liner plot of red mud and modified red mud. As seen in curve B, the adsorption and desorption curves did not coincide when the relative pressure was less than 0.7 , which meant that no micropores and mesopores existed in the red mud. In addition, a hysteresis loop was observed when the relative pressure was between 0.8 and 1.0, which meant that many macropores were present in red mud. As seen in curve A, when the relative pressure was less than 0.2 , the adsorption capacity was increased dramatically, which meant that the micropores existed in the modified red mud. When the relative pressure was between 0.4 and 1.0, a large hysteresis loop was observed, indicating more mesopores and macropores in modified red mud compared to red mud. The pore diameter distributions of red mud and modified red mud were shown in Figure 4. The red mud was constituted of mesopores in the range of $2-25 \mathrm{~nm}$, whereas the modified red mud was constituted of micropores $(1.2-2 \mathrm{~nm})$ and mesopores $(2-25 \mathrm{~nm})$. Pore structure parameters of red mud and modified red mud were shown in Table 2, and the specific surface area of modified red 
TABLE 2: Pore structure parameters of red mud and modified red mud.

\begin{tabular}{lcccc}
\hline Sample & Specific surface area $/ \mathrm{m}^{2} \cdot \mathrm{g}^{-1}$ & Total pore volume $/ \mathrm{cm}^{3} \cdot \mathrm{g}^{-1}$ & Micropore volume $/ \mathrm{cm}^{3} \cdot \mathrm{g}^{-1}$ & $\mathrm{Mesopore} \mathrm{volume} / \mathrm{cm}^{3} \cdot \mathrm{g}^{-1}$ \\
\hline Red mud & 8.12 & 0.115 & 0 & 0.118 \\
Modified red mud & 317.14 & 0.312 & 0.007 & 0.087 \\
\hline
\end{tabular}

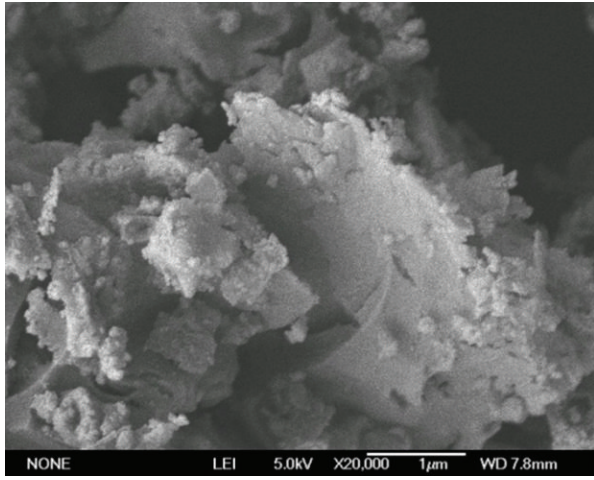

(a)

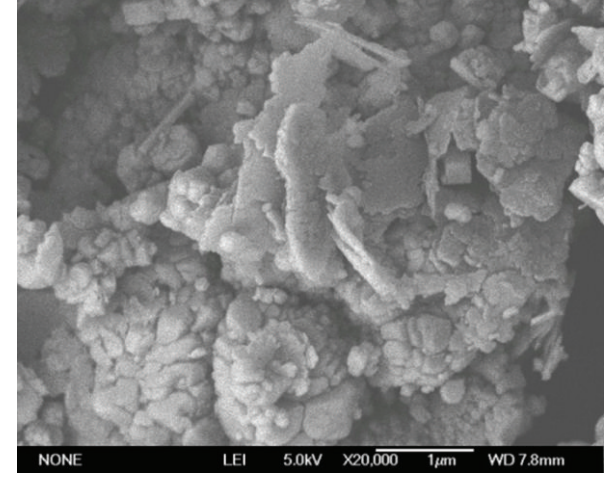

(b)

FIGURE 2: SEM images of red mud (a) and modified red mud (b).

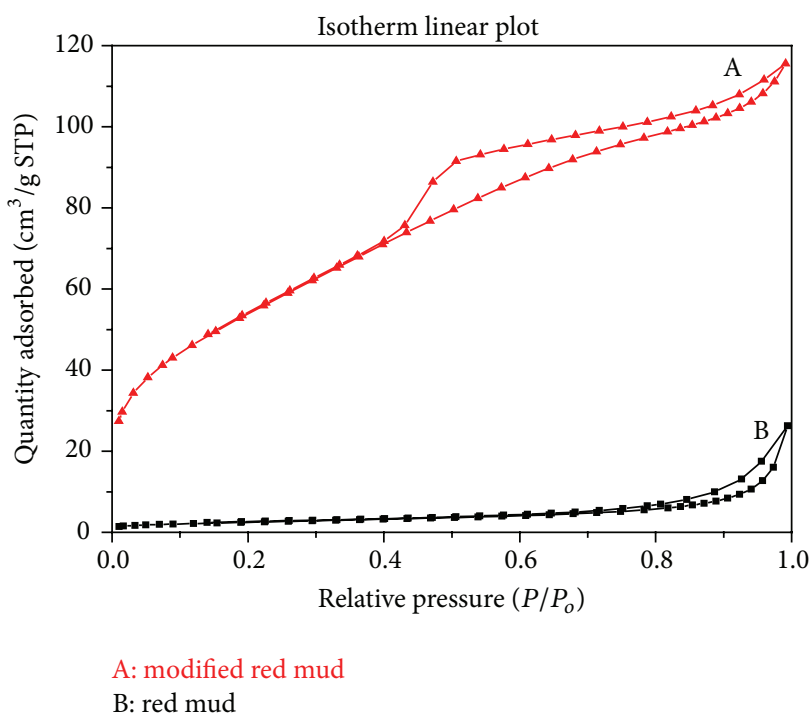

FIGURE 3: Isotherm linear plot of modified red mud (A) and red mud (B).

mud was $317.14 \mathrm{~m}^{2} / \mathrm{g}$, which was about 40 times higher than that of red mud. Moreover, no micropores existed in red mud, which was consistent with isotherm linear and pore diameter distribution analysis. Generally, the abundant pore structure was present in the modified red mud, which was beneficial for the enhancement of photocatalytic efficiency.

3.2. Photocatalytic Activity Test. Amount of $\mathrm{HCl}$ solution had a great effect on the removal percentage of $\mathrm{MO}$. As shown in Figure 5, the removal percentage of MO increased with the increasing amount of $\mathrm{HCl}$ solution and then decreased when the amount of $\mathrm{HCl}$ solution reached $90 \mathrm{~g}$. The obtained result

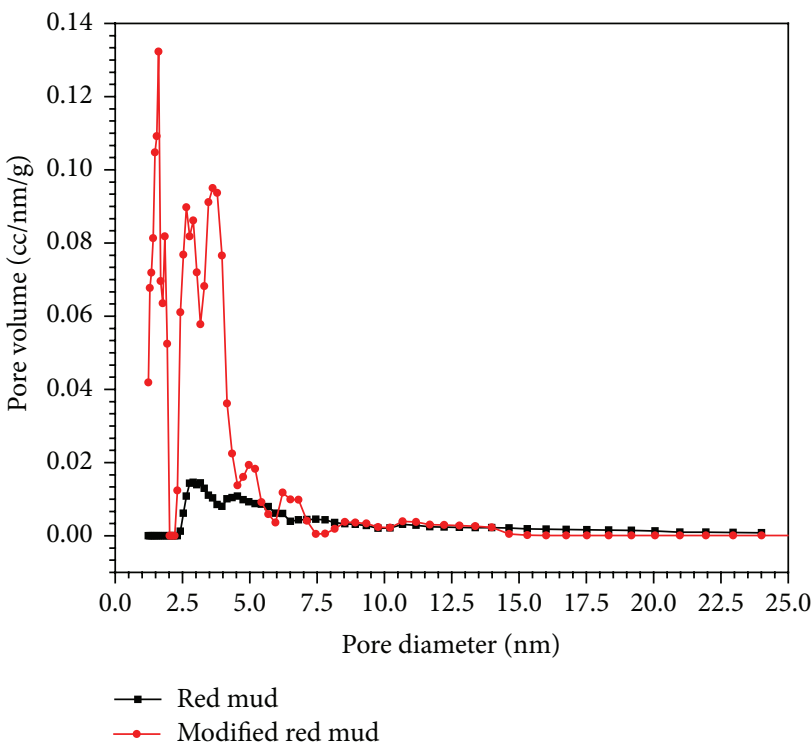

Figure 4: Pore diameter distribution curves of red mud and modified red mud.

indicated that the optimal amount of $\mathrm{HCl}$ solution was $90 \mathrm{~g}$, which was used for the preparation of modified red mud.

The photocatalytic activity of modified red mud was evaluated by monitoring the degradation rate of $\mathrm{MO}$ in aqueous solution, which was also compared with red mud. As shown in Figure 6, the degradation rate of MO was low in the dark and reached $10.2 \%$ after $50 \mathrm{~min}$, the low degradation rate can be mainly ascribed to the adsorption of MO on modified red mud, and the adsorption of MO occurs hardly in the absence of light. Under UV irradiation, the degradation rate of MO was low on red mud, while a significant enhancement 


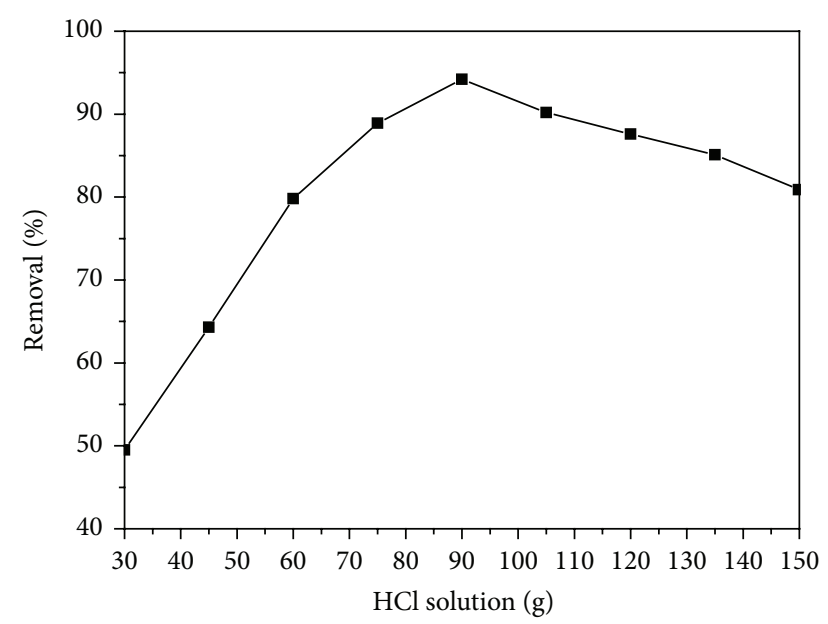

FIGURE 5: Effect of amount of $\mathrm{HCl}$ solution on the removal percentage of MO. Experimental conditions: $30 \mathrm{~g}$ red mud, $\mathrm{HCl} 5 \mathrm{~mol} / \mathrm{L}$, $5 \times 10^{-5} \mathrm{~mol} / \mathrm{L} \mathrm{MO}, 0.7 \mathrm{~g} / \mathrm{L}$ modified red mud, and irradiation time of $50 \mathrm{~min}$.

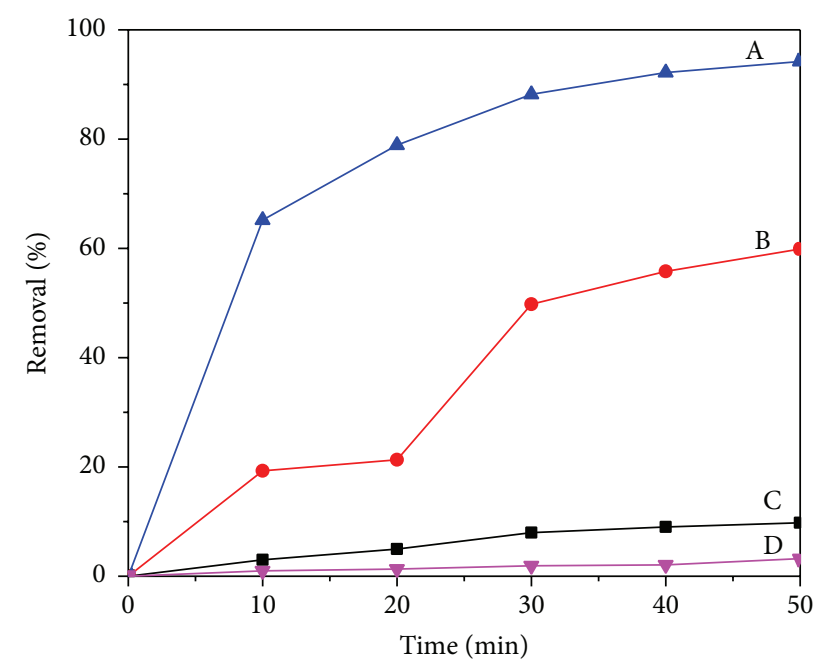

A: modified red mud with UV $\quad$ D: red mud with UV
B: modified red mud with visible light
C: modified red mud with dark

Figure 6: Comparison of degradation rate of MO under the different irradiation conditions.

was observed on modified red mud at a given time. After irradiation for $50 \mathrm{~min}$, the degradation rate of $\mathrm{MO}$ on modified red mud reached $94.2 \%$, indicating that modified red mud possesses a better dispersibility and more photoactive sites, causing an enhanced photodegradation of MO molecules. Under visible light irradiation (200w tungsten lamp), the degradation rate of MO kept a comparatively high value on modified red mud and reached $60.3 \%$ after irradiation for $50 \mathrm{~min}$. The high degradation rate can be due to the presence of $\mathrm{Fe}_{2} \mathrm{O}_{3}$ in modified red mud, and it has been reported that the $\mathrm{Fe}_{2} \mathrm{O}_{3}$-doped $\mathrm{TiO}_{2}$ photocatalyst will cause an obvious decrease in the band-gap energy of $\mathrm{TiO}_{2}$, showing a high

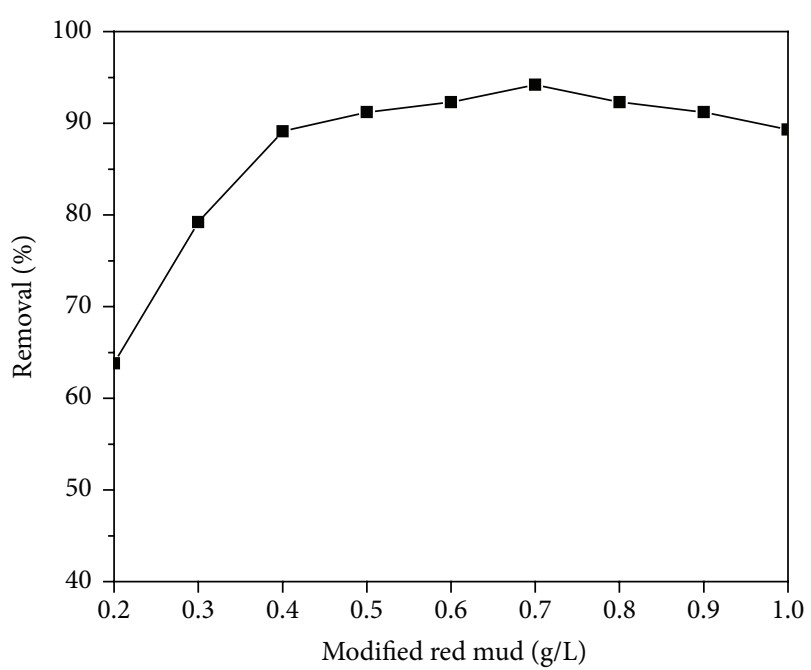

FIGURE 7: Effect of modified red mud amount on the removal percentage of MO. Experimental conditions: irradiation time of $50 \mathrm{~min}, 5 \times 10^{-5} \mathrm{~mol} / \mathrm{L} \mathrm{MO}$.

value in the degradation rate in the presence of visible light [16-18].

Photocatalytic degradation of MO depended on the amount of the modified red mud. Figure 7 shows the removal percentage of $\mathrm{MO}$ when the concentration of modified red mud was varied from 0.2 to $1.0 \mathrm{~g} / \mathrm{L}$. The removal percentage of MO increased with an increase in modified red mud concentration up to $0.7 \mathrm{~g} / \mathrm{L}$, and after that a further increase in modified red mud led to a slight decrease in the removal percentage of MO. Such results could be understood from two aspects. On one hand, the increase of modified red mud concentration will increase the number of photoactive sites and also the number of the MO molecules absorbed. And a further increase of the catalyst concentration beyond $0.7 \mathrm{~g} / \mathrm{L}$ may cause light scattering and screening effects, which will hinder the penetration of light and reduce the specific activity of the catalyst. On the other hand, at high catalyst concentration, it is difficult to maintain the homogeneous suspension due to particle agglomeration, which may also reduce the catalytic activity. Thus, the removal percentage of MO was decreased gradually. In this work, the optimum concentration of modified red mud is $0.7 \mathrm{~g} / \mathrm{L}$ for the photodegradation of MO.

The reusability of the photocatalyst is of great importance in the photodegradation of organic contaminants. To evaluate the reusability of modified red mud, the photodegradation experiment of $\mathrm{MO}$ was conducted repeatedly for ten times under the same experimental condition and the obtained results were tabulated in Figure 8. The removal percentage of MO kept $97.2 \%$ of its initial value after 10 cycles, indicating that the modified red mud can be reusable with meager loss in activity during the photocatalytic oxidation of MO molecules. The long-term storage stability was also investigated and the results were shown in Figure 9. After storage for 50 days, the removal percentage of MO decreased only $6.3 \%$ compared to the initial value. The results indicate the satisfactory 


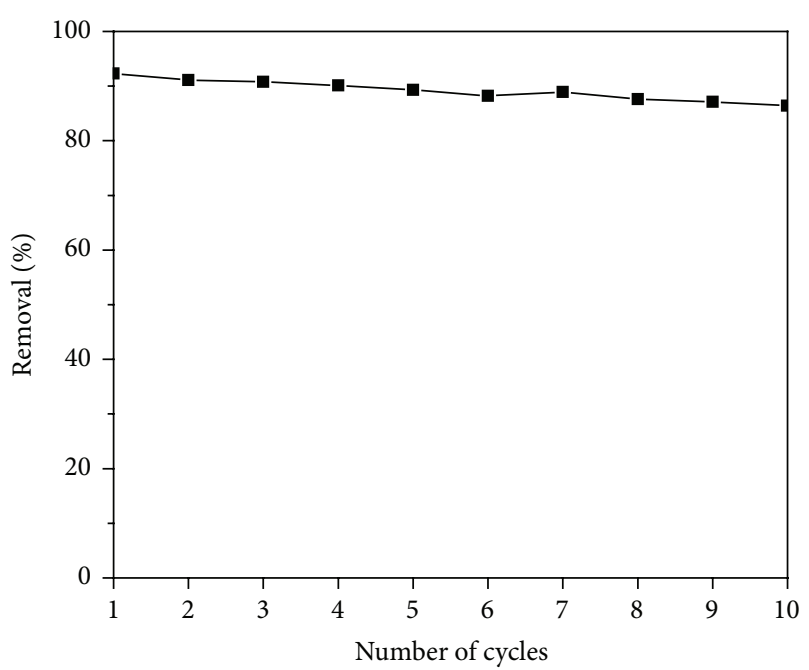

FIGURE 8: Reusability of modified red mud. Experimental conditions: $5 \times 10^{-5} \mathrm{~mol} / \mathrm{L} \mathrm{MO}, 0.7 \mathrm{~g} / \mathrm{L}$ modified red mud, and irradiation time of $50 \mathrm{~min}$.

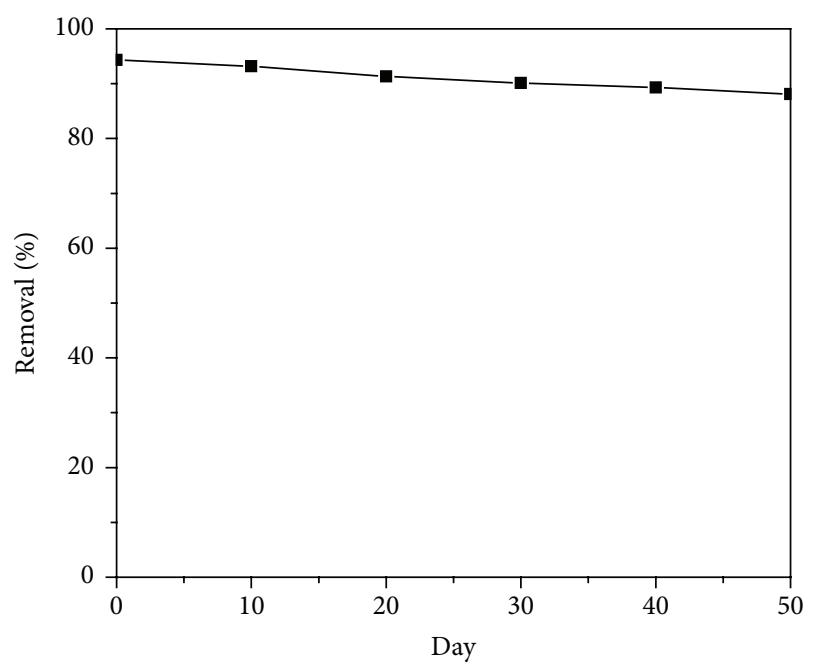

Figure 9: Long-term stability of modified red mud. Experimental conditions: $5 \times 10^{-5} \mathrm{~mol} / \mathrm{L} \mathrm{MO}, 0.7 \mathrm{~g} / \mathrm{L}$ modified red mud, and irradiation time of $50 \mathrm{~min}$.

reusability and stability of modified red mud towards MO photodegradation.

\section{Conclusions}

The modified red mud with large specific surface area and rich pore structure was prepared by $\mathrm{HCl}$ leaching of red mud. The photocatalytic performance of the modified red mud was evaluated and the obtained results indicated that the modified red mud possessed high photodegradation activity, stability, and reusability for the degradation of $\mathrm{MO}$ under UV irradiation. The photocatalyst had a potential application to purify polluted water, and it also provided a new way for utilization of red mud.

\section{Conflict of Interests}

The authors declare that there is no conflict of interests regarding the publication of this paper.

\section{Acknowledgments}

This work was supported by the Research Foundation for Youth Scholars of Higher Education of Henan Province (2013GGJS-047), the Fundamental Research Funds for the Universities of Henan Province (NSFRF140201 and NSFRF140601), and the Opening Project of Henan Key Discipline Open Laboratory of Mining Engineering Materials (no. MEM13-4).

\section{References}

[1] I. Smičiklas, S. Smiljanić, A. Perić-Grujić, M. Šljivić-Ivanović, M. Mitrić, and D. Antonović, "Effect of acid treatment on red mud properties with implications on $\mathrm{Ni}(\mathrm{II})$ sorption and stability," Chemical Engineering Journal, vol. 242, pp. 27-35, 2014.

[2] M. D. Niculescu, "Study on chemically modified red mud for pollutants capturing from industrial effluents," Revista De Chimie, vol. 65, no. 11, pp. 1310-1313, 2014.

[3] M. Shirzad-Siboni, S. J. Jafari, O. Giahi, I. Kim, S.-M. Lee, and J.K. Yang, "Removal of acid blue 113 and reactive black 5 dye from aqueous solutions by activated red mud," Journal of Industrial and Engineering Chemistry, vol. 20, no. 4, pp. 1432-1437, 2014.

[4] W. C. Liu, X. Q. Chen, W. X. Li, Y. F. Yu, and K. Yan, "Environmental assessment, management and utilization of red mud in China," Journal of Cleaner Production, vol. 84, no. 1, pp. 606-610, 2014.

[5] M. Matsuoka and M. Anpo, "Local structures, excited states, and photocatalytic reactivities of highly dispersed catalysts constructed within zeolites," Journal of Photochemistry and Photobiology C: Photochemistry Reviews, vol. 3, no. 3, pp. 225252, 2003.

[6] L. Zhu, Z.-D. Meng, and W.-C. Oh, "MWCNT-based $\mathrm{Ag}_{2} \mathrm{~S}_{-} \mathrm{TiO}_{2}$ nanocomposites photocatalyst: ultrasound-assisted synthesis, characterization, and enhanced catalytic efficiency," Journal of Nanomaterials, vol. 2012, Article ID 586526, 10 pages, 2012.

[7] W. J. Jiang, M. Zhang, J. Wang, Y. F. Liu, and Y. F. Zhu, “Dramatic visible activity in phenol degradation of TCNQ@ $\mathrm{TiO}_{2}$ photocatalyst with core-shell structure," Applied Catalysis B: Environmental, vol. 160-161, no. 1, pp. 44-50, 2014.

[8] Y.-S. Wang, J.-H. Shen, and J.-J. Horng, "Chromate enhanced visible light driven $\mathrm{TiO}_{2}$ photocatalytic mechanism on Acid Orange 7 photodegradation," Journal of Hazardous Materials, vol. 274, pp. 420-427, 2014.

[9] L. Xu, H. Zang, Q. Zhang et al., "Photocatalytic degradation of atrazine by $\mathrm{H}_{3} \mathrm{PW}_{12} \mathrm{O}_{40} / \mathrm{Ag}-\mathrm{TiO}_{2}$ : kinetics, mechanism and degradation pathways," Chemical Engineering Journal, vol. 232, pp. 174-182, 2013.

[10] P. M. Álvarez, J. Jaramillo, F. López-Piñero, and P. K. Plucinski, "Preparation and characterization of magnetic $\mathrm{TiO}_{2}$ nanoparticles and their utilization for the degradation of emerging pollutants in water," Applied Catalysis B: Environmental, vol. 100, no. 1-2, pp. 338-345, 2010.

[11] P. P. Hankare, R. P. Patil, A. V. Jadhav, K. M. Garadkar, and R. Sasikala, "Enhanced photocatalytic degradation of methyl red 
and thymol blue using titania-alumina-zinc ferrite nanocomposite," Applied Catalysis B: Environmental, vol. 107, no. 3-4, pp. 333-339, 2011.

[12] H. N. Gu, N. Wang, S. Y. Liu, and Y. J. Tian, "The research of composition and particle of red mud by sintering process," Rock and Mineral Analysis, vol. 31, no. 2, pp. 312-317, 2012.

[13] C. R. Borra, Y. Pontikes, K. Binnemans, and T. Van Gerven, "Leaching of rare earths from bauxite residue (red mud)," Minerals Engineering, vol. 76, pp. 20-27, 2015.

[14] Y. L. Pang and A. Z. Abdullah, "Effect of low $\mathrm{Fe}^{3+}$ doping on characteristics, sonocatalytic activity and reusability of $\mathrm{TiO}_{2}$ nanotubes catalysts for removal of Rhodamine B from water," Journal of Hazardous Materials, vol. 235-236, pp. 326-335, 2012.

[15] P. W. Huo, Y. S. Yan, S. T. Li et al., " $\mathrm{H}_{2} \mathrm{O}_{2}$ modified surface of $\mathrm{TiO}_{2} /$ fly-ash cenospheres and enhanced photocatalytic activity on methylene blue," Desalination, vol. 263, no. 1-3, pp. 258-263, 2010.

[16] A. Banisharif, A. A. Khodadadi, Y. Mortazavi et al., "Highly active $\mathrm{Fe}_{2} \mathrm{O}_{3}$-doped $\mathrm{TiO}_{2}$ photocatalyst for degradation of trichloroethylene in air under UV and visible light irradiation: experimental and computational studies," Applied Catalysis B: Environmental, vol. 165, pp. 209-221, 2015.

[17] M. A. Mahadik, S. S. Shinde, V. S. Mohite et al., "Visible light catalysis of rhodamine $\mathrm{B}$ using nanostructured $\mathrm{Fe}_{2} \mathrm{O}_{3}, \mathrm{TiO}_{2}$ and $\mathrm{TiO}_{2} / \mathrm{Fe}_{2} \mathrm{O}_{3}$ thin films," Journal of Photochemistry and Photobiology B: Biology, vol. 133, pp. 90-98, 2014.

[18] B. Ayoubi-Feiz, S. Aber, A. Khataee, and E. Alipour, "Preparation and application of $\alpha-\mathrm{Fe}_{2} \mathrm{O}_{3} / \mathrm{TiO}_{2} /$ activated charcoal plate nanocomposite as an electrode for electrosorption-assisted visible light photoelectrocatalytic process," Journal of Molecular Catalysis A: Chemical, vol. 395, pp. 440-448, 2014. 

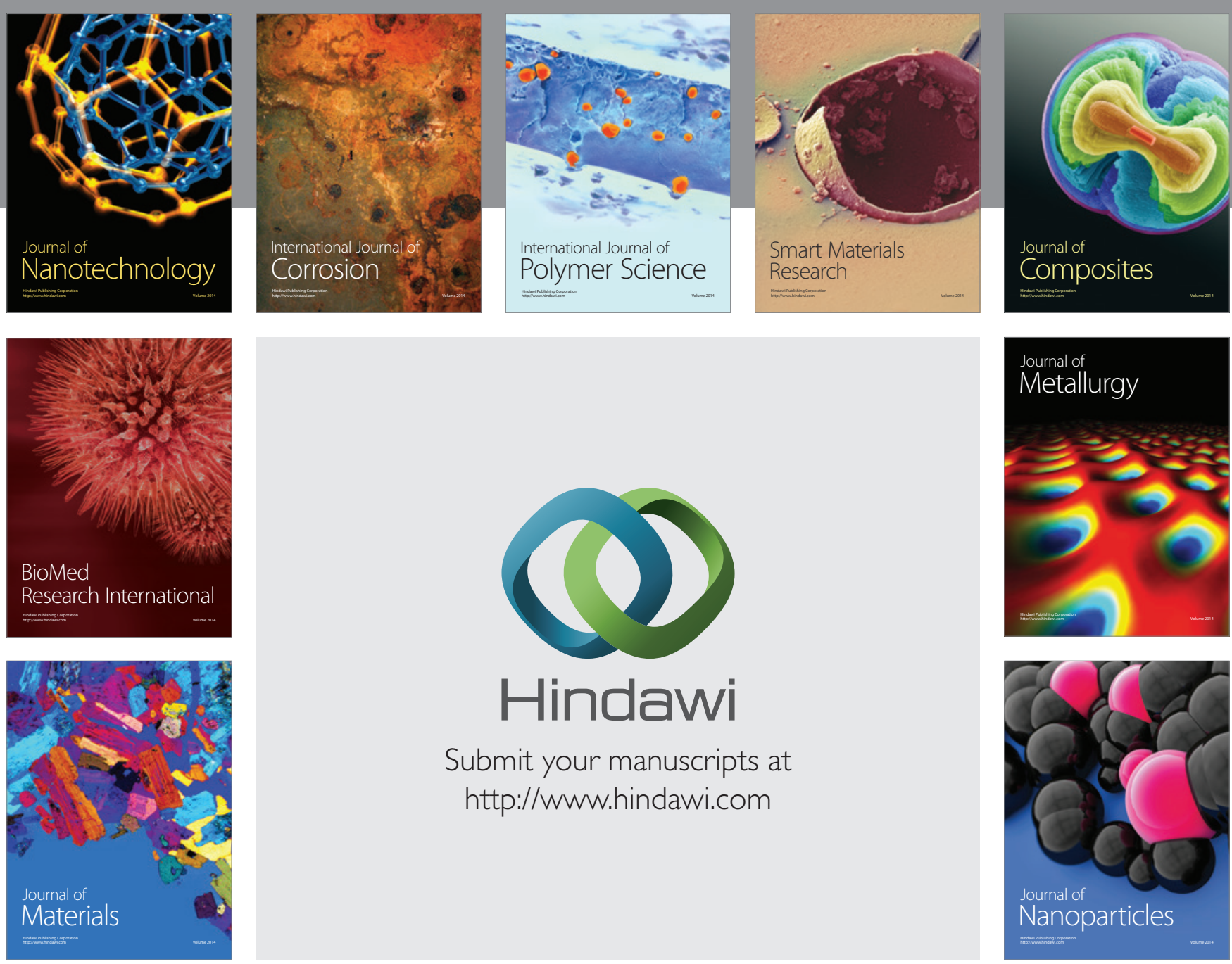

Submit your manuscripts at http://www.hindawi.com
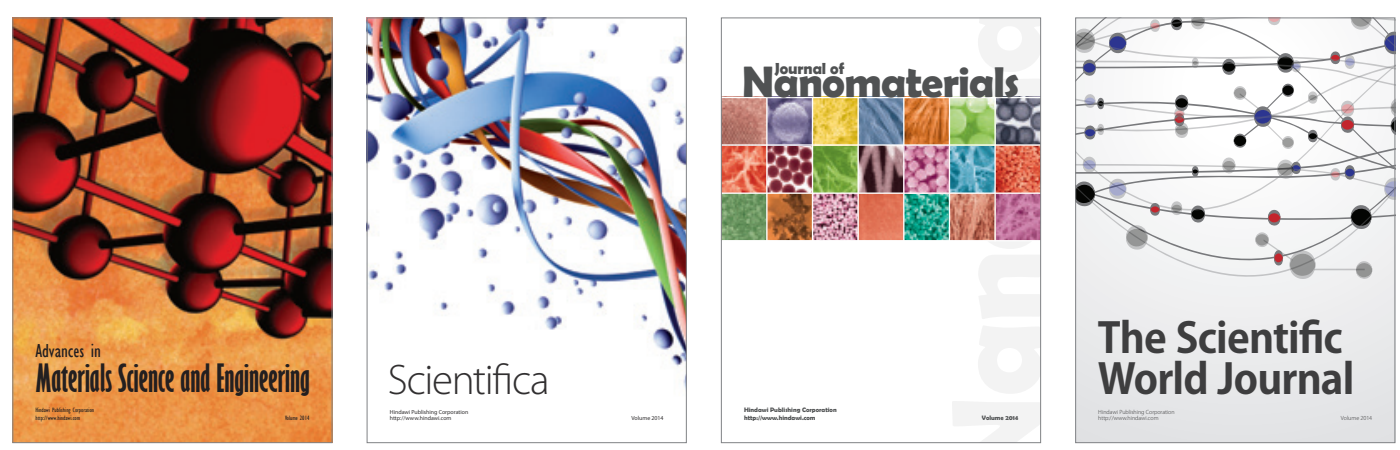

\section{The Scientific World Journal}
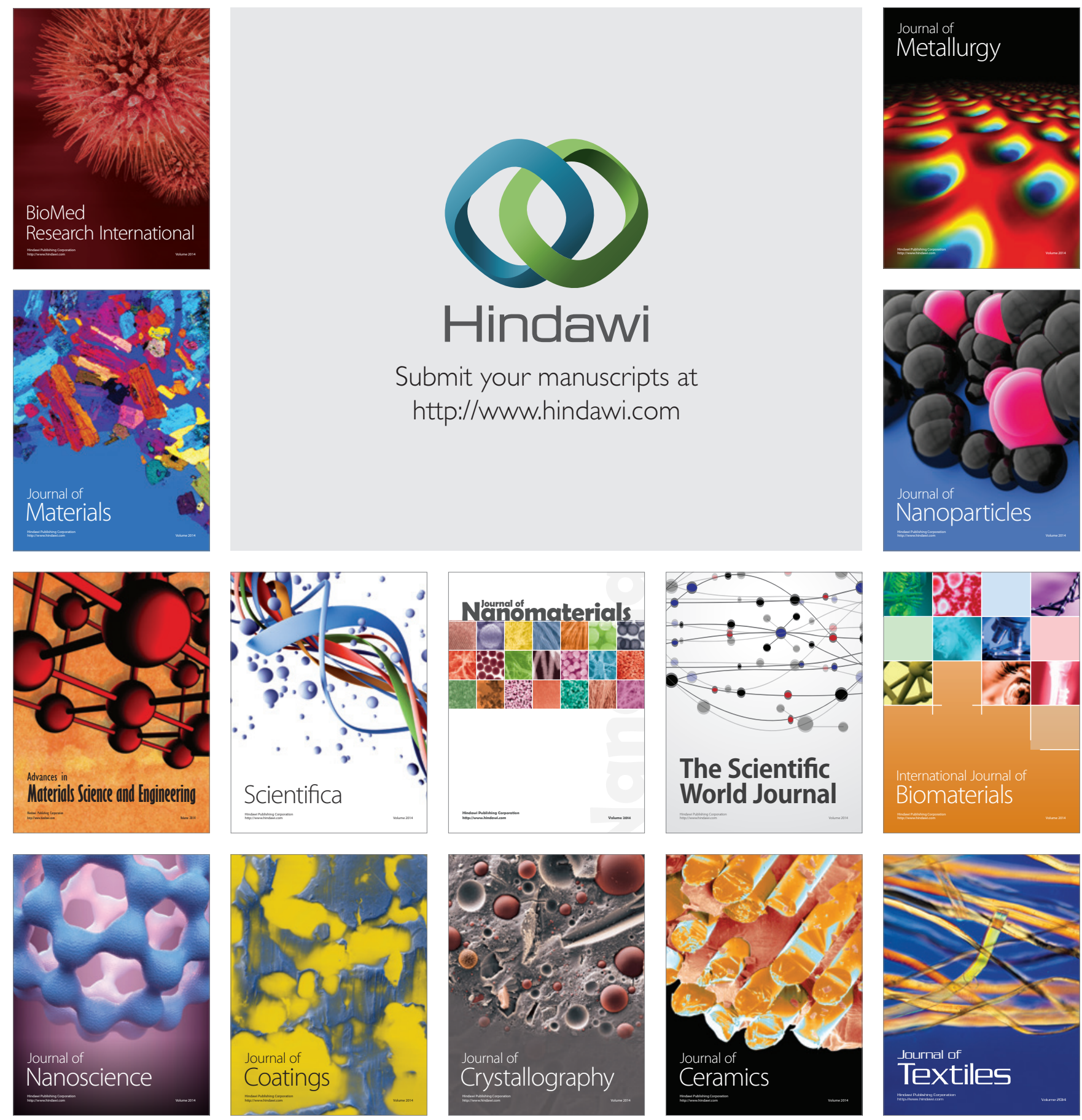